\title{
Dr. Klaus Pistrick retires
}

\section{Karl Hammer}

Published online: 10 July 2018

(C) Springer Nature B.V. 2018

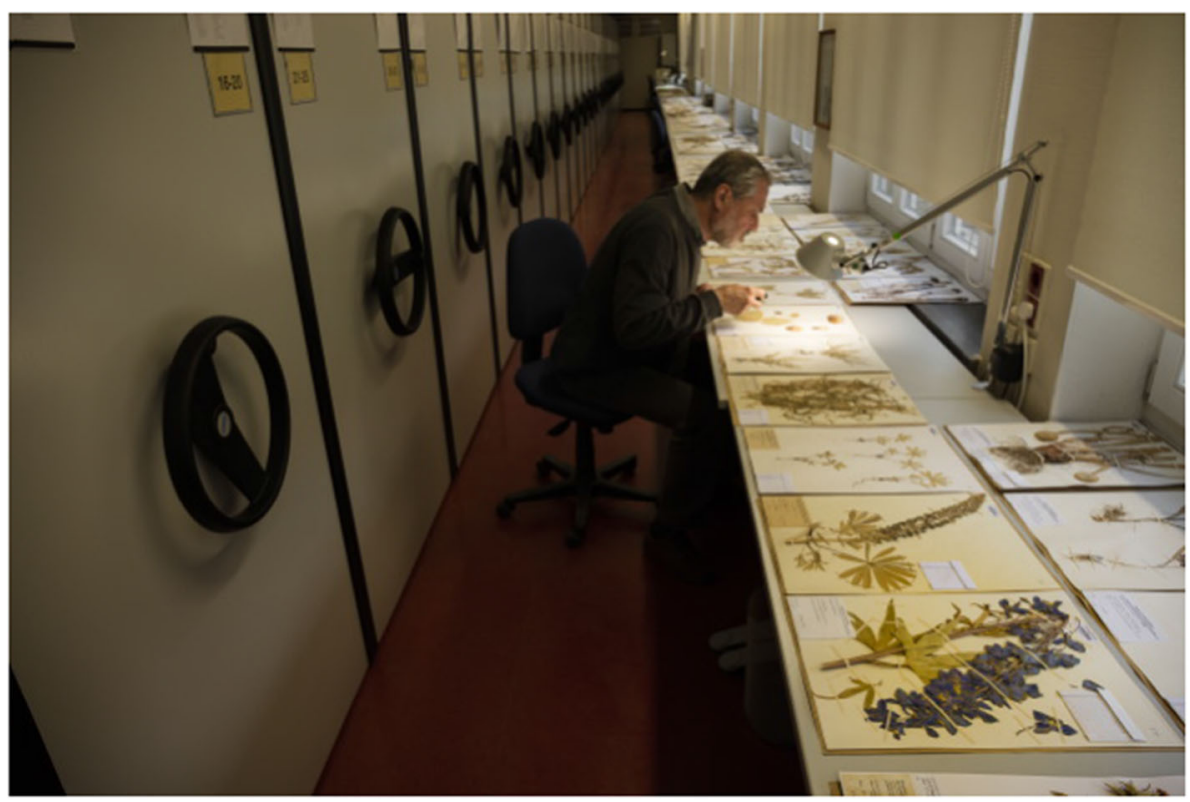

Photo G. Steinmetz

Dr. Klaus Pistrick from the Institute of Plant Genetics and Crop Plant Research (IPK) in Gatersleben joined the Managing Editorial Board of Genetic Resources

K. Hammer $(\bowtie)$

Gatersleben, Germany

e-mail: hammer@ipk-gatersleben.de and Crop Evolution nearly 20 years ago [GRACE, vol. 47 (1) 2000]. After Dr. Peter Hanelt had retired as Editor-in-Chief (Hammer and Pistrick, GRACE 47: 105-106), K. Pistrick took his new responsibility on and, in the following years, he actively supported the development of the journal in service of the research community that studies all aspects of plant genetic 
resources. He contributed to the strategic development of the journal (see also introductory article by Pistrick and Hammer 2003: 50 years of "Kulturpflanze"/ "GRACE"-retrospect and prospect, GRACE 50: $1-2)$.

Klaus Pistrick, a classical taxonomist, has been working since 1979 at the Institute in Gatersleben. Presently, he is curator of the Gatersleben Herbarium (GAT), within the working group Experimental Taxonomy of the Genebank Department. His doctoral thesis from 1985 was a dissertation on Raphanus. The Gatersleben Herbarium is of world-wide importance for cultivated plants and their wild relatives. Klaus Pistrick collected actively plant genetic resources in several areas of the world between Tunisia and Mongolia, and shaped the Gatersleben model for multi-crop missions (see Hammer, Fritsch, Hanelt, Knüpffer, Pistrick in Guarino et al. (eds), 1995: Collecting Plant Genetic Diversity-Technical Guidelines, pp. 713-725). He was awarded by the
Mongolian Academy of Sciences in 2012 with the reputational Khublai-Khan-Gold Medal. His work on plant genetic resources and the genus Allium was particularly noted.

For many years, he used his enormous experiences in plant taxonomy, morphology and plant genetic resources for GRACE and I hope that he will also be available in future as a colleague and friend for the editorial board of GRACE.

Behind every successful man, there is a strong women. Erika Pistrick, who is organizing the technical management of the journal in Gatersleben, will also retire at the end of 2018. Over the years, she became an invaluable resource with increasing importance for the journal, clearly documented by her review "Research in plant genetic resources 1978-2003: general index of the second 25 volumes 'Kulturpflanze'/"GRACE'” (together with K. Pistrick and K. Hammer), GRACE 51: 1-109. 